\title{
Understanding Corn Belt farmer perspectives on climate change to inform engagement strategies for adaptation and mitigation
}

\author{
J.G. Arbuckle Jr., J. Hobbs, A. Loy, L.W. Morton, L.S. Prokopy, and J. Tyndall
}

\begin{abstract}
Development of extension and outreach that effectively engage farmers in climate change adaptation and/or mitigation activities can be informed by an improved understanding of farmers' perspectives on climate change and related impacts. This research employed latent class analysis (LCA) to analyze data from a survey of 4,778 farmers from 11 US Corn Belt states. The research focused on two related research questions: (1) to what degree do farmers differ on key measures of beliefs about climate change, experience with extreme weather, perceived risks to agriculture, efficacy, and level of support for public and private adaptive and mitigative action; and (2) are there potential areas of common ground among farmers? Results indicate that farmers have highly heterogeneous perspectives, and six distinct classes of farmers are identified. We label these as the following: the concerned $(14 \%)$, the uneasy $(25 \%)$, the uncertain $(25 \%)$, the unconcerned $(13 \%)$, the confident $(18 \%)$, and the detached (5\%). These groups of farmers differ primarily in terms of beliefs about climate change, the degree to which they had experienced extreme weather, and risk perceptions. Despite substantial differences on these variables, areas of similarity were discerned on variables measuring farmers' (1) confidence that they will be able to deal with increases in weather variability and (2) support for public and private efforts to help farmers adapt to increased weather variability. These results can inform segmented approaches to outreach that target subpopulations of farmers as well as broader engagement strategies that would reach wider populations. Further, findings suggest that strategies with specific reference to climate change might be most effective in engaging the subpopulations of farmers who believe that climate change is occurring and a threat, but that use of less charged terms such as weather variability would likely be more effective with a broader range of farmers. Outreach efforts that (1) appeal to farmers' problem solving capacity and (2) employ terms such as "weather variability" instead of more charged terms such as "climate change" are more likely to be effective with a wider farmer audience.
\end{abstract}

Key words: adaptation — agriculture—climate change—communication—extension—latent class analysis

\begin{abstract}
Climate change-related threats to agriculture represent threats to food and fuel supplies at local and global scales (IFPRI 2010; IPCC 2007; NRC 2010) and have led to mounting calls for adaptation and mitigation strategies (Climate Change Position Statement Working Group 2011; Howden et al. 2007; IPCC 2007; McCarl 2010). Farmers are vulnerable to changing climate conditions and are the group on whom the dual tasks of adaption and mitigation in agriculture largely fall (Berry et al. 2006). Emerging research
\end{abstract}

Although concepts of vulnerability, resilience, hazard, and risk are well developed in the global change literature, methodological development to apply these concepts to adaptation planning and assessment lag substantively (Walthall et al. 2012). Further, effective climate science communication with farmers and bidirectional engagement in climate-related adaptation and mitigation strategies are lacking (Arbuckle et al. 2013a, 2013 b). If agricultural production systems are to be adapted to a changing climate, the development of extension and outreach strategies that effectively support farmer adaptive action is critically important. This means we need to better understand variations among farmers in terms of their belief systems; their personal experiences with climate-related risks; and their confidence that technologies, insurance, and their skills are sufficient (or not) to address these perceived risks and hazards.

The challenges of communicating climate science to the public are well documented. Despite near-universal scientific agreement that climate change is happening and due largely to human activities (Anderegg et al. 2010; Doran and Zimmerman 2009), public understanding of the phenomenon remains highly unsettled (Weber 2010), and uncertainty and variance in beliefs have eroded public support for climate policy and constrained action (Hulme 2009; McCright and Dunlap 2010; Weber and Stern 2011). Indeed, while surveys of the general public find that majorities believe that climate change is occurring, proportions vary significantly over time and among populations (Gallup 2012; Leiserowitz et al. 2013a; Nisbet and Myers 2007; Pew Research Center 2012). In addition, public understanding of climate change and its potential

J. Gordon Arbuckle Jr. is an associate professor of sociology and an extension sociologist at lowa State University in Ames, lowa. Jon Hobbs is a postdoctoral scholar in the Jet Propulsion Laboratory at the California Institute of Technology in Pasadena, California. Adam Loy is an assistant professor of statistics at Lawrence University in Appleton, Wisconsin. Lois Wright Morton is a professor of sociology and extension sociologist at lowa State University in Ames, lowa. Linda Stalker Prokopy is an associate professor in the Department of Forestry and Natural Resources at Purdue University in West Lafayette, Indiana. John Tyndall is an associate professor in the Department of Natural Resources Ecology and Management at lowa State University in Ames, lowa. 
consequences has been further muddled by organized campaigns designed to "manufacture uncertainty" and undermine attempts to generate large-scale societal responses (Dunlap 2013).

Such disconnects between scientific consensus and public understanding of climate change have led to substantial reflection in the climate science community on the reasons for and potential solutions to this cognitive breach. The role that science communication might play in maintaining or bridging the divide represents a major thread of research in this area (Moser 2010). In particular, recent work has centered on identifying shortcomings in past efforts to increase public knowledge about climate change or induce behavioral change to inform more effective communication and outreach (Groffman et al. 2010; Hulme 2009).

A central theme of recent thinking on climate science communication has been a critique of what is generally termed the "deficit model" of communication. The deficit approach is based on an assumption that the public simply lacks knowledge of key issues, and if those deficits can be filled, understanding and behavior change will follow (Brossard and Lewenstein 2010). It is a linear, one-way model of communication in which information flows from the scientific community to an undifferentiated public. A growing recognition that understanding can be strongly mediated by context, especially cultural milieu, that influences the formation of beliefs (Kahan et al. 2010), has led to a movement toward communications models that are less linear and more dialogic and participatory in nature (Brossard and Lewenstein 2010). Calls for such a shift in approach are increasingly common in the area of climate science communication (Hulme 2009; Moser 2010), as it has become apparent that the politicization of climate change and similar factors have undermined attempts to mobilize societal action (Kahan 2012; McCright and Dunlap 2010).

A similar recognition of the limitations of the deficit model of communication has been occurring in the realm of soil and water conservation. In agriculture, communication of science to farmers has long formed the core of extension and outreach strategies (Rogers 2003). The traditional extension approach is a classic example of the deficit model of communication, in which information and technologies are generated by scientists and transferred by extension and outreach entities to farmers, who are viewed as passive recipients of knowledge and innovation (Leeuwis 2004). While the approach has been largely effective in the transfer of profit-oriented agronomic information and innovations (Ruttan 1996), it has been much less so in the agrienvironmental arena (Nowak 2013). Nevertheless, extension and natural resource conservation agencies in the United States continue to employ topdown, prescriptive approaches that do not engage the creative, problem-solving capacity of farmers (Nowak 2013).

A growing body of research shows that innovation processes in agriculture that employ iterative, cooperative approaches that link scientists, extension and outreach professionals, and farmers can be highly effective (Leeuwis 2004; Morton and Brown 2011). Similar to the dialogic models that are emerging to engage sectors of the general public in deliberations on climate change science and policy (Groffman et al. 2010; Hulme 2009; Moser 2010), these efforts seek to involve farmers and other agricultural actors in participatory, collective action toward reducing the environmental impacts of agriculture while increasing resiliency (Morton and Brown 2011). These engagement processes deliberately connect those with differing beliefs, knowledge and skills but with shared interests in finding solutions by creating space for farmers to learn from their peers, scientists, and educators.

Pursuit of such interactive approaches requires knowledge of audiences' perspectives on the issues that are to be addressed (Leeuwis 2004; Morton and Brown 2011). Accordingly, this research employed latent class analysis (LCA) to gain a better understanding of how farmers differ and/or are similar in terms of their knowledge, experience, and attitudes regarding climate change and agriculture. Such knowledge is needed to guide the development of engagement strategies that strengthen farmer willingness and capacity to undertake adaptation and mitigation actions. This article reports the results of LCA models run with 34 variables measuring US Corn Belt farmers' climate beliefs, perceptions of hazard, risk, personal efficacy, and support for adaptation and mitigation action.

The LCA approach to segmenting populations according to perspectives on climate change has antecedent in the literature.A series of studies conducted through the Yale Project on Climate Change Communication and the
George Mason University Center for Climate Change Communication have employed LCA to categorize the general public into discrete groups based on beliefs, behaviors, and policy preferences (Leiserowitz et al. 2013b). As Maibach et al. (2011a) explained, the principal aim of their research has been to identify and characterize audience segments within the general population to inform the creation of public engagement campaigns tailored and targeted to like-minded subpopulations within the general public.

While we looked to this thread of research to inform our efforts, our objectives contrast in an important way. The LCA approach is typically employed to discern differences within a given population; however, similarities within a population are also important to understand. Knowledge of how subgroups of farmers differ or are similar in terms of their beliefs about climate change, perceptions of associated risks, and support for action are critical for development of both targeted and broad-based communication strategies. The LCA approach employed in this research seeks to build new knowledge to guide development of diverse engagement strategies that resonate with specific as well as broader populations of farmers.

\section{Materials and Methods}

Sampling Approach. Data were collected through a survey of farmers from 11 US Corn Belt states: Illinois, Indiana, Iowa, Kansas, Michigan, Minnesota, Missouri, Nebraska, Ohio, South Dakota, and Wisconsin (figure 1). The geographic scope of the survey represents a region responsible for more than one-third of the global corn (Zea mays L.) supply (USDA NASS 2011; USDA FAS 2012) and is defined as major crop areas for corn and soybean (Glycine max L.) by the USDA (USDA 1994).

The population of interest for this survey was larger-scale corn farmers. The rationale for the selection of farmers from this population was twofold. First, the projects that funded the survey are focused on enhancing the resilience of grain-based agricultural systems. Second, larger-scale operations comprise a disproportionately large amount of acreage relative to their numbers. Across the 11 states, farm operations with 2007 gross sales of at least US $\$ 100,000$ represented $27 \%$ of farms with cropland but cultivateed $78 \%$ of all cropland acres (USDA NASS 2009). The sample frame included only farm operations with greater than 80 acres of corn 


\section{Figure 1}

Map of the US with the 22 hydrologic unit codes (HUC6) watersheds comprising the survey sampling frame strata outlined in black. The watersheds are overlaid on a map of acres of corn harvested by county in 2007 (NASS 2009).

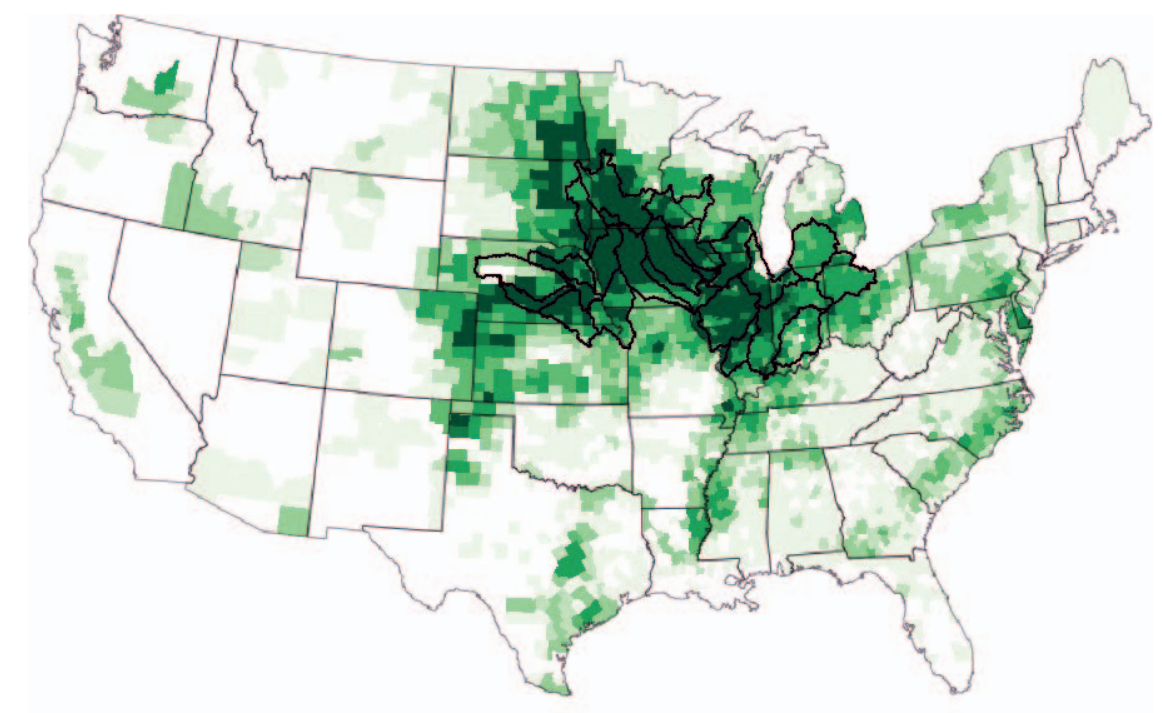

Legend Area (ac) HUC6 watershed borders $\square$

\begin{tabular}{|l|l|l|l}
$<5,000$ & 10,000 to 24,999 & 50,000 to 99,999 & $150,000+$ \\
5,000 to 9,999 & 25,000 to 49,999 & 100,000 to 149,999
\end{tabular}$\quad$ L

production and a minimum of US $\$ 100,000$ of gross sales. Our sample was drawn from the USDA National Agricultural Statistics Service (NASS) Census of Agriculture master list, which is the most comprehensive and up-to-date list of US farmers. The survey was also conducted by NASS.

The survey was mailed in February of 2012 to 18,707 eligible farmers using a three-wave mailing process: first a survey was mailed, then a postcard reminder, and then a final survey to nonresponders. Completed surveys were received from 4,778 farmers for an effective response rate of $26 \%$. To test for nonresponse bias, we used Census of Agriculture data that NASS provided for both respondents and nonrespondents. We tested for differences between respondents and nonrespondents on 28 variables measuring farm enterprise (e.g., farm size, crops, and livestock produced) and farmer (e.g., age and sex) characteristics. No meaningful differences between respondents and nonrespondents were detected, indicating that our sample is representative of the target population and statistics calculated for respondents will lead to unbiased estimates of the population parameters of interest (see Arbuckle et al. [2013a] for a more detailed description of the sampling method and nonresponse evaluation).
Analytical Approach. We employ LCA to assign farmers to discrete classes based on responses to 34 survey items measuring five underlying individual-level constructs that are central to understanding farmer perspectives on climate change and agriculture: experienced environmental hazards; beliefs about climate change; perceived climate risks, perceived efficacy, and support for adaptive and mitigative action. Latent class analysis is a model-based clustering technique that, like traditional nonhierarchical clustering techniques such as $k$-means, strives to explain the associations observed in multivariate data by clustering cases according to an unobserved (latent) nominal variable. The advantage of using latent class analysis is that clustering is based on a statistical model; thus, rigorous statistical tests to aid in the selection of the number of clusters and techniques for handling missing responses are available (Magidson and Vermunt 2002; Linzer 2011). Additionally, since clustering is based on a model for the population, the resulting model fit provides richer information than simple cluster means and the solution can be explored and summarized in a variety of ways.

Latent class analysis is an iterative procedure that identifies clusters in mul- tivariate data by fitting latent class models with increasing numbers of latent classes (Magidson and Vermunt 2004). The latent class model assumes that the population is comprised of a mixture of $R$ distinct classes (types) of individuals with each class having distinct response distributions for each survey item. It is additionally assumed that these classes explain the associations between the observed responses such that, within each class the responses are mutually independent. However, these underlying classes are unobserved (i.e., latent), so class membership is assigned probabilistically based on the observed responses.

Formally, the vector of responses, $y_{i}$, for individual $i$, is modeled as being generated by a mixture distribution

$f_{\text {Mix }}\left(y_{i}\right)=\sum_{r=1}^{R} p_{r} f_{r}\left(y_{i}\right)$

where $p_{r}$ is the proportion of the population consisting of class $r$, and $f_{r}\left(y_{i}\right)$ denotes the probability density function for class $r$ - that is, the function describing the probability that an individual in class $r$ will provide a specific response pattern. Assuming mutual independence of the responses within each class, $f_{r}\left(y_{i}\right)$ is expressed as

$f_{r}\left(y_{i}\right)=\prod_{j=1}^{J} \prod_{k=1}^{K_{j}}\left(\pi_{j k}^{(r)}\right)^{\gamma i j k}$

where $\left(\pi_{j k}^{(r)}\right)$ denotes the probability of an individual in class $r$ giving response $k$ to question $j$, and $\gamma_{i j k}$ is an indicator of whether individual $i$ gave response $k$ to question $j$. The model parameters $p_{r}$ and $\left(\pi_{i k}^{(r)}\right)$ are estimated by maximum likelihood (analysis carried out in $R$ using the poLCA package [R Core Team 2012; Linzer 2011]), and, given these estimates, the assignment of individuals to latent classes is based on the (posterior) membership probabilities, which are calculated using Bayes' theorem. That is, given $\hat{p}_{r}$ and $\hat{\pi}_{j k}^{(r)}$, the probability that individual $i$ belongs to class $r_{i}$ is given by

$\widetilde{P r}\left(r_{i} \mid y_{i}\right)=\frac{\hat{p_{r}} f\left(y_{i}\right)}{\sum_{l=1}^{R} \hat{p_{l}} f\left(y_{i}\right)}$

and the individual is assigned to the class for which this posterior probability is larg- 
est. For individuals with complete data, the posterior probability for one of the classes is typically close to one and for the remaining classes is nearly zero.

Variables in the Model. As noted above, our analysis focuses on 34 variables that measure aspects of five constructs of farmer perspectives on climate change. The five broad categories were based on the conceptual categories employed by Maibach et al. (2011a; 2011b) in their LCA analyses of general public data. They are experience with environmental hazards such as floods and droughts, beliefs about climate change and its causes, concerns about potential climate change-related risks to agriculture, confidence in capacity to respond effectively to climate change, and support for private and public adaptive and mitigative action. The 34 survey items and their units of measurement are presented in table 1. Descriptive statistics for the survey items are presented in Loy et al. 2013. The following paragraphs provide a brief description of the variables in each category and outline the rationale for inclusion of the variables in the model.

Research on adaptive and mitigative response to natural hazards finds that behavioral adjustment is shaped largely by "beliefs about the existence and characteristics of a natural hazard" (Nigg and Mileti 2002). Central to those beliefs are actual experience of hazards, and numerous studies have linked experience with extreme events to attitudes about climate change (Akerlof et al. 2013; Brody et al. 2008; Myers et al. 2013; Spence et al. 2011). Four survey items measuring recent experience of agriculture-related hazards are included in the analysis. Specifically, respondents were asked to report whether they had experienced significant drought, problems with saturated soils or ponding, a stream/river flooding, or significant soil erosion over the five years prior to the survey (table 1). A single item measuring whether any streams or rivers run through their farm was also included in this set of items.

Closely related to experienced hazard are perceptions regarding the risks that climate change may pose. Research with the general public has found fairly strong relationships between perceived risks from climate change and willingness to modify behavior in response (O'Connor et al. 1999, 2005). In short, people who believe that adverse events are more likely to occur are more apt to take preparatory action. In agriculture, as Howden et al. (2007) emphasize, if farmers do not perceive climate change as a threat, they will not likely undertake adaptive or mitigative actions. Twelve measures of climate risk perception are included in the analysis. Ten items were developed drawing on literature that outlines the predicted impacts of climate change on agriculture in the US Midwest (Hatfield et al. 2011; Rogovska and Cruse 2011; SWCS 2011). Respondents were asked to report their level of concern regarding potential problems with longer dry periods and drought, more frequent extreme rains, and increases in incidence of crop disease, flooding, weed pressure, insect pressure, heat stress on crops, saturated soils and ponding, erosion, and loss of nutrients into waterways (table 1). Two additional measures of perceived risk were positively and negatively worded items that asked farmers to rate their agreement or disagreement with statements that their farm operation would likely benefit from/be harmed by climate change.

The analysis includes a single question measuring beliefs about climate change and its causes. Respondents were asked to select one of five options that best reflected their beliefs about climate change (table 1). Three options stated that climate change is occurring and allowed respondents to indicate whether it is due mostly to human activities, due mostly to natural changes in the environment, or due more or less equally to humans and natural change. A fourth category allowed respondents to indicate that they were uncertain due to lack of sufficient evidence, and the fifth option was that climate change is not occurring.

Perceived efficacy, or capacity to respond to challenges associated with climate change, has received increasing attention in the literature (Ding et al. 2009; Kellstedt et al. 2008). The concept was originally conceptualized as self-efficacy, and defined as individuals' "beliefs about their capabilities to exercise control over their own level of functioning and over events that affect their lives" (Bandura 1991), or the ability to perform certain behaviors in response to contextual factors (Ajzen 2002). In the climate change literature, the concept of (self-)efficacy has generally been employed in a more collective sense, to understand individuals' perceptions of their role in larger-scale mitigation actions, such as reducing greenhouse gas (GHG) emissions or otherwise measure their perceived ability to influence climate change outcomes (Kellstedt et al. 2008).
Our measures focus on perceived efficacy, or capacity to respond to the potential impacts of climate change on agriculture, at both the individual and collective levels. Three individual-level efficacy items follow the original conceptual meaning of self-efficacy as articulated by Bandura (1991) and Ajzen (2002), with self-efficacy referring to farmers' self-assessed capacity to deal with climate change-related shifts in weather patterns. These individual-focused items include confidence that current practices will maintain long-term farm operation success, knowledge and technical skill to deal with weather-related threats to the farm operation, and financial capability to deal with weather-related threats (table 1). Three items assess the perceptions of collective-level capacity to respond included confidence that human ingenuity will enable people to adapt to changes, the capacity of crop insurance to protect farm viability, and concern that current best management practice technologies are not sufficient to protect farmland from the impacts of climate change.

The final category of variables measures support for a number of individual, organizational, and government-level actions to address climate change and related impacts. Ten items asked farmers to express their agreement or disagreement about whether different types of entities should take action to prepare for climate change or increased weather variability. Four of those items centered on whether farmers should individually or collectively take additional steps to protect farmland from increased weather variability, and whether they should invest in additional drainage or irrigation. Four of the items focused on agriculture-related agencies and organizations - extension, state and federal agencies, seed companies, and farm organizations-and whether they should act to help farmers prepare for increased weather variability. Two items asked farmers to express their agreement or disagreement about whether government should do more to reduce GHG emissions, and whether they as individuals should reduce GHG emissions from their farm operations (table 1). Thus, eight items centered on adaptation to increases in weather variability and two on mitigation.

\section{Results and Discussion}

Latent Class Analysis Model Results. Several latent class models were fit to the 34 variables shown in table 1 . Part of the process 


\section{Table 1}

Description of survey questions used in latent class analysis. The question column provides the question category and label used in figure 3. The description column provides the survey's actual wording for the question. All variables are numerically scaled from a minimum of o to a maximum of 1 for the summaries in figures 3 and 4 . The mean and standard deviation for the entire sample are provided here. The response column provides the type of response options, which are defined as follows:

Agreement-Strongly Disagree (o), Disagree (0.25), Uncertain (0.5), Agree (0.75), and Strongly Agree (1)

Concern-Not Concerned (o), Slightly Concerned (0.33), Concerned (0.67), and Very Concerned (1)

Confidence-Not at all Confident (o), Somewhat Confident (0.33), Confident (0.67), and Very Confident (1)

Question
$\begin{aligned} & \text { Climate change belief } \\ & \text { BELIEF }\end{aligned}$
about climate change:
a) Climate change is occurring, and it is caused mostly by natural
changes in the environment $(0.5)$
b) Climate change is occurring, and it is caused mostly by
human activities (1)
c) Climate change is occurring, and it is caused more or less equally by
natural changes in the environment and human activities $(0.75)$
d) Climate change is not occurring $(0)$
e) There is not sufficient evidence to know with certainty whether climate
change is occurring or not $(0.25)$

Experienced hazard

$\begin{array}{ll}\text { HAZ1 } & \text { Experienced significant drought in the last five years } \\ \text { HAZ2 } & \text { Problems with saturated soils or ponding in the last five years } \\ \text { HAZ3 } & \text { Creeks, streams or rivers running through farmland } \\ \text { HAZ4 } & \text { Experienced stream/river flooding in the last five years } \\ \text { HAZ5 } & \text { Some land farmed has experienced significant soil erosion, last five years }\end{array}$

Response

Mean

Sd

Choose one of a to e $\quad 0.527$

0.261

Perceived risk

RISK1 Increased flooding

RISK2 Longer dry periods and drought

RISK3 Increased weed pressure

RISK4 Increased insect pressure

RISK5 Higher incidence of crop disease

RISK6 More frequent extreme rains

RISK7

Increases in saturated soils and ponded water

RISK8 Increased heat stress on crops

RISK9 Increased loss of nutrients into waterways

RISK10 Increased soil erosion

RISK11 My farm operation will likely benefit from climate change

RISK12 My farm operation will likely be harmed by climate change

Efficacy

EFFIC1 How confident are you that current practices will maintain the long-term success of your farm operation?

EFFIC2

I have the knowledge and technical skill to deal with any weather-related threats to the viability of my farm operation.

EFFIC3 I have the financial capability to deal with any weather-related threats to the viability of my farm operation.

EFFIC4

Climate change is not a big issue because human ingenuity will enable us to adapt to changes.

EFFIC5 Crop insurance and other programs will protect the viability of my farm operation regardless of weather.

EFFIC6 I am concerned that available best management practice technologies are not effective enough to protect the land I farm from the impacts of climate change.

\begin{tabular}{|c|c|c|}
\hline Yes (1) or no (0) & 0.297 & 0.457 \\
\hline Yes (1) or no (0) & 0.740 & 0.438 \\
\hline Yes (1) or no (0) & 0.755 & 0.430 \\
\hline Yes (1) or no (0) & 0.370 & 0.482 \\
\hline Agreement (5) & 0.391 & 0.266 \\
\hline Concern (4) & 0.310 & 0.310 \\
\hline Concern (4) & 0.555 & 0.281 \\
\hline Concern (4) & 0.486 & 0.281 \\
\hline Concern (4) & 0.493 & 0.262 \\
\hline Concern (4) & 0.497 & 0.255 \\
\hline Concern (4) & 0.494 & 0.291 \\
\hline Concern (4) & 0.434 & 0.303 \\
\hline Concern (4) & 0.513 & 0.269 \\
\hline Concern (4) & 0.380 & 0.286 \\
\hline Concern (4) & 0.418 & 0.298 \\
\hline Agreement (5) & 0.411 & 0.191 \\
\hline Agreement (5) & 0.496 & 0.196 \\
\hline Confidence (4) & 0.624 & 0.242 \\
\hline Agreement (5) & 0.592 & 0.215 \\
\hline Agreement (5) & 0.565 & 0.232 \\
\hline Agreement (5) & 0.506 & 0.227 \\
\hline Agreement (5) & 0.508 & 0.227 \\
\hline Agreement (5) & 0.473 & 0.198 \\
\hline
\end{tabular}


Table 1 continued

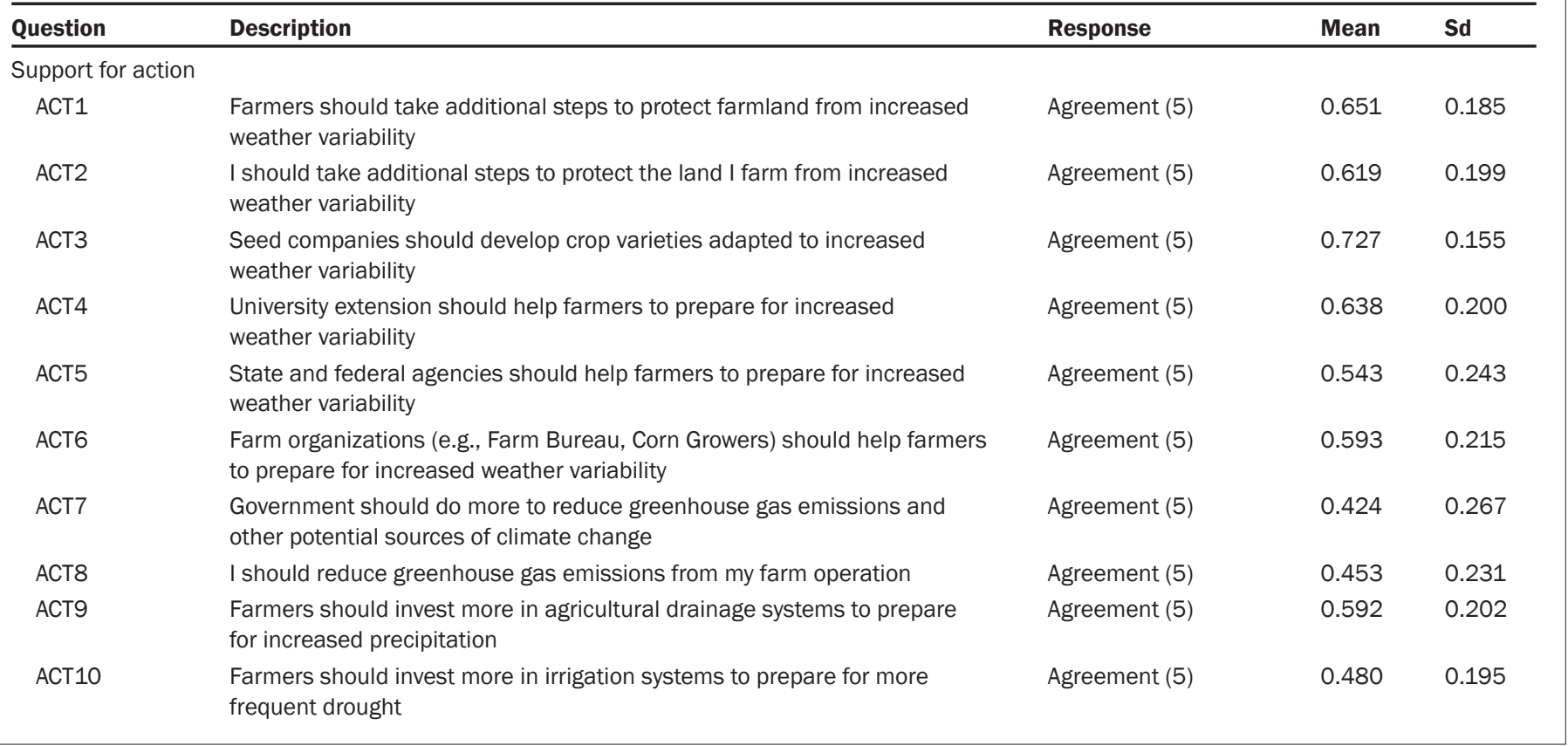

of latent class analysis involves selecting the number of latent classes $R$, with a different number of latent classes implying a different latent class model. Latent class analysis model selection combines objective and subjective criteria. Overall model fit can be summarized objectively with information criteria such as Bayesian Information Criterion (BIC), which is a fit statistic that combines the maximumlikelihood goodness of fit with a penalty for model complexity. Subjective considerations involve balancing sufficiently complex models that offer distinct classes while avoiding models with classes that differ in minor, subtle ways.

Our model selection process involved fitting models ranging from 3 to 15 latent classes. In latent class analysis, the number of model parameters grows substantially as the number of classes increase, so a smaller model that fits adequately may be preferable to a larger, better-fitting model if the larger model yields only subtle differences between some of the classes. In our investigation, the models with the fewest ( 3 to 4 ) classes fit the data poorly. The 9- to 12-class models achieved optimal BIC values. While statistically optimal, the practical differences between classes for these models were very slight. Following Maibach et al. (2011a), we assessed parameter estimates for slightly smaller models ranging from 6 to 9 classes and determined that a six-class model $(R=6)$ provided a satisfactory BIC while maintaining distinction among the classes and adequate interpretability.
Figure 2 displays the estimated class membership proportions $p$ for the six-class model. The first class makes up just under $14 \%$ of the population. The second and third classes together make up nearly half of the population. Class 4 represents $13 \%$ of the farmers, class 5 contains $18 \%$, and class 6 is the smallest at $5 \%$.

Distributions by Class. The fitted latent class model provides rich distributional information within each of the six latent classes, including a full estimated response distribution for each categorical survey item included in the model. Examining these full distributions is a challenging task, so interpretation can be aided by devising summaries of the class-level response distributions. All of the variables included in the model are either dichotomous or consist of categories that can be ordered. To improve our capacity to visually interpret differences and similarities across variables with dissimilar measures, we developed a standardized numerical scale that could be graphed in parallel coordinate plots. Standardized scores were calculated for all variables, ranging from zero to one with zero representing the lowest category (no, strongly disagree, not concerned, and not at all confident) and one representing the highest category (yes, strongly agree, very concerned, and very confident). Intermediate categories are assigned values linearly between the minimum (0) and maximum (1) (for detailed discussion of this method, see Theus [2008] and Wegman [1990]). While this is not formal inference on the distinctions among the classes, these summaries are valuable tools for exploring the model fit across the six latent classes. The means of these standardized numerical values for each class are shown in figure 3 . For ease of presentation and interpretation, these values are subdivided into four groups of survey items: experienced hazard, beliefs and perceived risk, efficacy, and support for action.

The top panel of figure 3 summarizes the class-level distributions of experienced hazards. Across all classes, drought (HAZ1) was reported less frequently than saturated soils, ponding or stream/river flooding (HAZ2, HAZ4). Classes 1 and 2 stand out as having the highest levels of experienced hazards, with more than $80 \%$ reporting problems with saturated soils or ponding and more than half reporting significant flooding. These two classes are also characterized by more than $40 \%$ of individuals who agreed or strongly agreed that their land had recently experienced significant soil erosion (HAZ5). The subpopulation in class 5 does not have high levels of reported soil erosion, but experiences with saturated soils, ponding, and flooding are comparable to classes 1 and 2. Class 4 contains the lowest proportions of farmers who experienced problems with drought or saturated soils, and class 6 contains the smallest proportion who experienced significant soil erosion.

Class distributions for climate change belief and perceived risk are shown in the second panel of figure 3. Class 1 includes the largest 


\section{Figure 2}

Estimated class membership percentage for the six-class model.

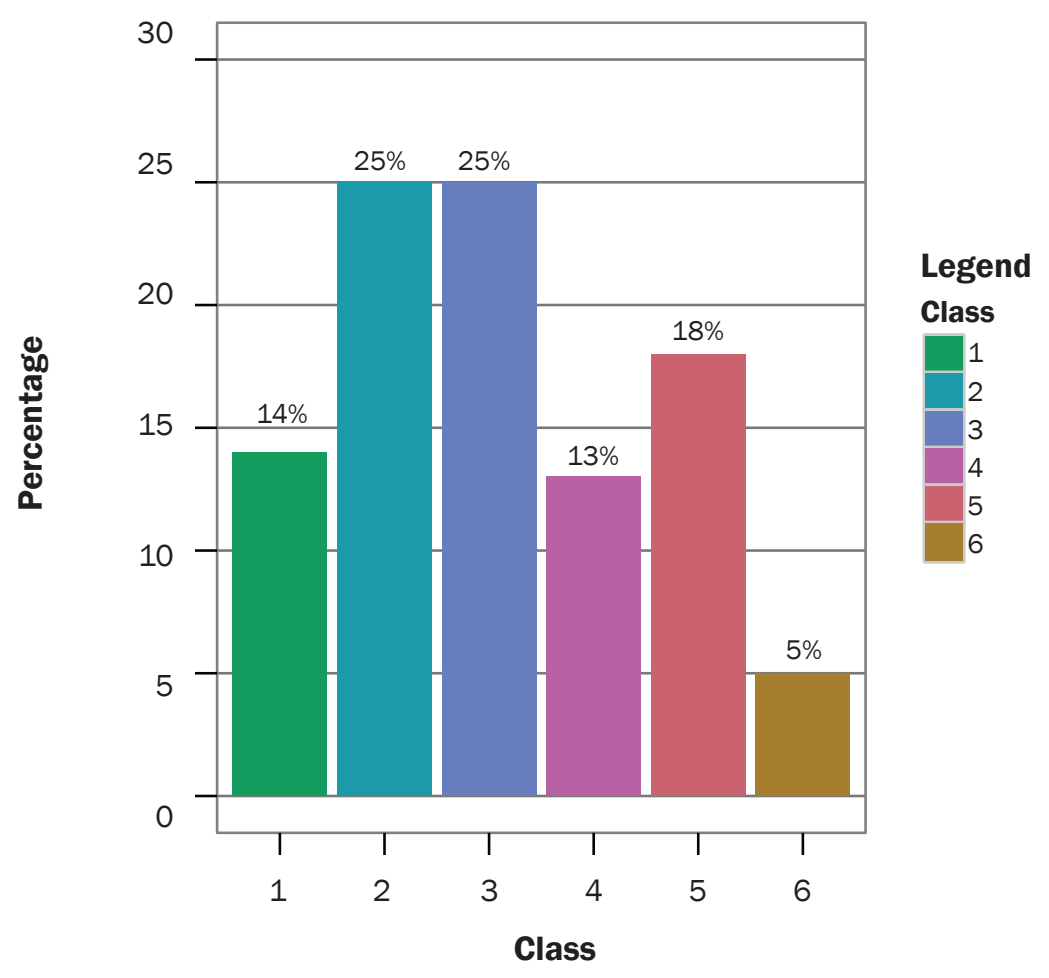

proportion of farmers who believe climate change is caused mostly by human activities. Classes 4,5 , and 6 contain substantial proportions of farmers who believe that there is insufficient evidence to determine whether climate change is occurring. The Class 6 subpopulation has the highest proportion of farmers who reported that they did not believe that climate change is occurring.

Similar patterns in class-level distributions are apparent for the 12 perceived risk items. Class 1 consistently has the highest proportion of farmers who are concerned or very concerned about climate-related risks to agriculture. Class 2 follows closely behind on these perceived risks, with particularly high levels for extreme rains (RISK6), saturated soils/ponding (RISK7), and increased heat stress (RISK8). Classes 3 and 5 generally have moderate levels of concern, with class 3 having noticeably lower levels of concern about flooding (RISK1), extreme rains and saturated soils/ponding. Class 6 has generally low levels of concern, with nearly half of this class strongly disagreeing that their farm operations would be harmed by climate change (RISK12). Except for this item, class 4 actually expresses the lowest levels of concern on the other perceived risk items, aligning with from climate change (RISK11). the low levels of experienced hazards for this group. One perceived risk item shows very little variability across the six classes. Among all classes, uncertain was the most frequently selected response category for the statement that farm operations would likely benefit

Variables measuring efficacy are summarized in the third panel of figure 3 . These distributions have generally the opposite orientation to the perceived risk items. Individuals in class 6 have the highest levels of agreement that their knowledge and technical skill (EFFIC2), their financial capacity (EFFIC3) and general human ingenuity (EFFIC4) will ensure the viability of their operations and enable humans to adapt to climate change. All classes have generally high levels on these efficacy items, although over half of the class 1 subpopulation disagreed that climate change is not a big issue because human ingenuity will allow for adaptation. There was very little variability among classes on the item crop insurance (EFFIC5), with the distribution concentrated at uncertain or slightly tending to agreement.

The bottom panel of figure 3 depicts the class-level support for adaptive and mitigative action related to weather variability and climate change. Class 6 shows substantial separation from the other classes on this collection of variables, consistently having the lowest levels of support for action. In class 6, the only action item with substantial levels of support is for the development of adapted crop varieties by seed companies (ACT3). Class 5 consistently has the second-lowest levels of support for action, and farmers in this subpopulation particularly disagree that action should be taken to reduce greenhouse gas emissions both individually (ACT8) and through government action (ACT7). This pattern aligns with the climate change belief distribution for class 5 , which is dominated by the uncertain and natural change options. Class 4, previously characterized by low levels of experienced hazards and perceived climate risks, shows modest agreement on most of the action items. On the other hand, class 3 has slightly higher levels of support for action, even though levels of experienced hazards were somewhat lower. Class 2 has comparable levels of support to class 3 on most items but shows substantially higher agreement that farmers should invest more in agricultural drainage systems (ACT9). Class 1 has the highest level of support for action overall. The strength of agreement among class 1 farmers is particularly evident in support of individual farmer action to protect the land (ACT1, ACT2) and regarding support from extension (ACT4) and government agencies (ACT5). None of the six classes had a majority of farmers who agree that individual farmers or the government should act to reduce greenhouse gas emissions.

Characterizing Differences between Classes. As proposed in the introduction, a primary objective of this research is to identify meaningful differences between subgroups of farmers. To highlight differences between classes, we plot each on a radar chart according to their rank by standardized mean values for each category of variables (figure 4). The standardized mean values are aggregate measures across all items in each category as presented in table 1. Based on these ranks/ scores, we give each class a label to help differentiate it and facilitate discussion of the variation of farmers across classes, much as was done by Maibach et al. (2011a) and Leiserowitz et al. (2013b).

We label class 1 "the concerned" (figure 4). This group was the most likely to believe that climate change is occurring and due to human activity, expressed the highest levels of concern about the potential impacts of climate 


\section{Figure 3}

Class means for a 6-class model using 34 variables. Numeric labels and different colors indicate class membership number for each variable, mean pair. The vertical axis is scaled to range from the minimum to maximum possible values for each variable. Variables with an asterisk $\left({ }^{*}\right)$ have been reverse-coded. Variables are grouped by questions about (a) experienced hazard, (b) beliefs and perceived risk, (c) efficacy, and (d) support for action number for each variable, mean pair.

(a)

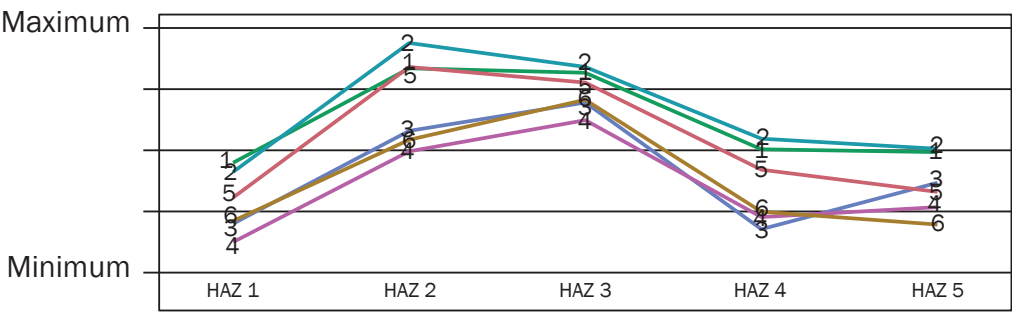

(b)

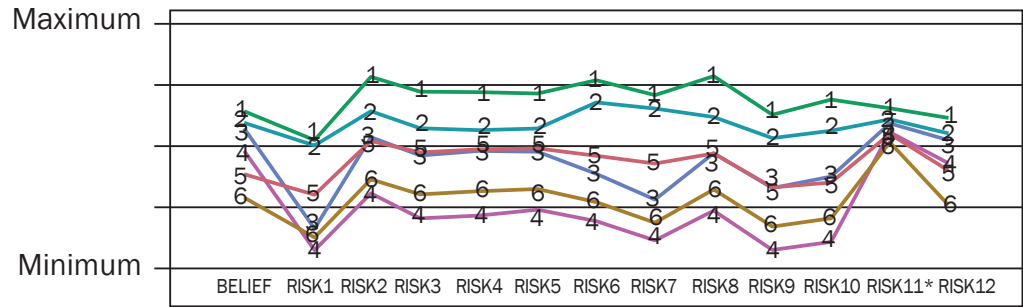

Question

(c)

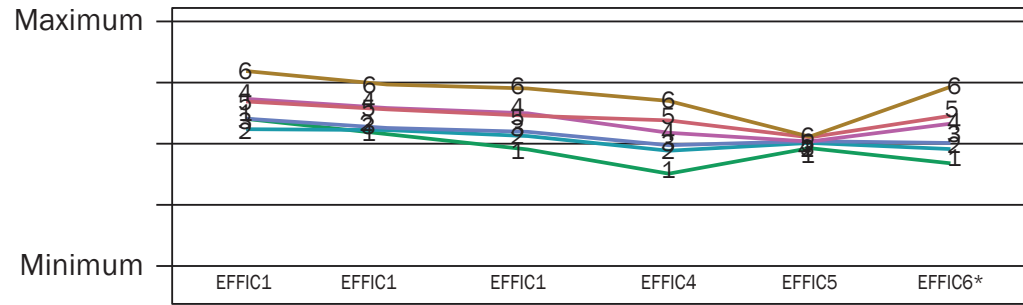

Question

(d)

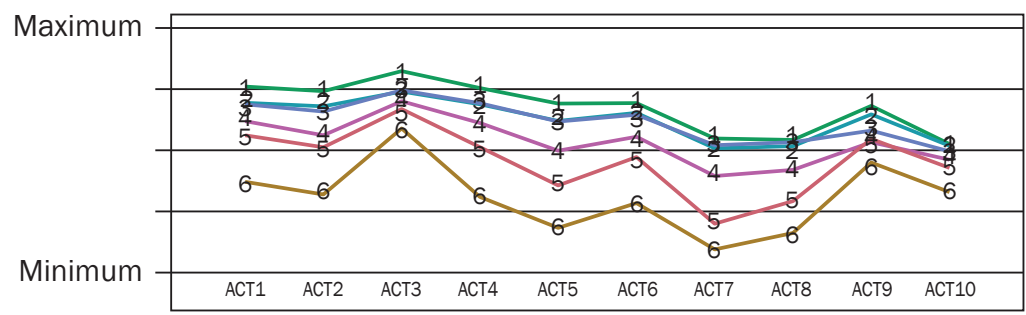

Question change, reported the second-highest levels of experienced hazard, and was most supportive of adaptive and mitigative actions. They also scored lowest on the efficacy measures. This group believes that climate change is occurring, they are worried about it, they are not confident that they can cope, and they most support individual, private sector, and government action toward adaptation to increased weather variability and mitigation through reduction of greenhouse gas emissions.

Class 2, comprising an estimated $25 \%$ of the population (figure 2), is labeled "the uneasy" (figure 4). This class also has relatively high average scores for the belief, perceived risk, and support for action categories. The uneasy reported the highest levels of experienced hazard, and the second lowest efficacy scores. Class 3 , also at $25 \%$ of farmers, is labeled "the uncertain." As can be seen from the figure, this group occupies the middle ground across most of the categories, but leans slightly toward belief and support for action. Class 4, "the unconcerned," had the lowest levels of concern about the potential impacts of climate change and the lowest levels of experienced hazard. Farmers in this group also ranked third in efficacy, indicating that they have more confidence in their ability to adapt than their counterparts in the previous three classes.

We label class 5 "the confident" (figure 4). Class 5 is the third largest class, at 18\% (figure 1).We use the term confident because although farmers in this class expressed the third highest levels of concern about impacts and the third highest levels of experienced hazard, these are balanced by the second highest efficacy score. Farmers in this group also tended not to believe in climate change, nor did they support adaption and mitigation action. Taken together, the results indicate that this group is confident in their capacity to adapt to changes.

Class 6 is labeled "the detached" (figure 4). This class scored lowest on belief, second lowest on risk and hazard, and lowest on support for action. As a group, they had the highest efficacy scores, by a substantial margin. Overall, the results indicate that the detached group has not dealt with weather-related adversity in recent years, and believes strongly that their current practices and strategies, knowledge, and technical skill will be sufficient to cope with any future weather variability for their operations. They do not support action focused on adapting to increases in weather variability or reducing GHGs, either by other individuals or agricultural agencies and orga- 


\section{Figure 4}

Radar charts showing class rank for each category of variables by standardized mean values: (a) class 1, concerned; (b) class 2, uneasy; (c) class 3, uncertain; (d) class 4, unconcerned; (e) class 5, confident; and (f) class 6, detached.

(a)

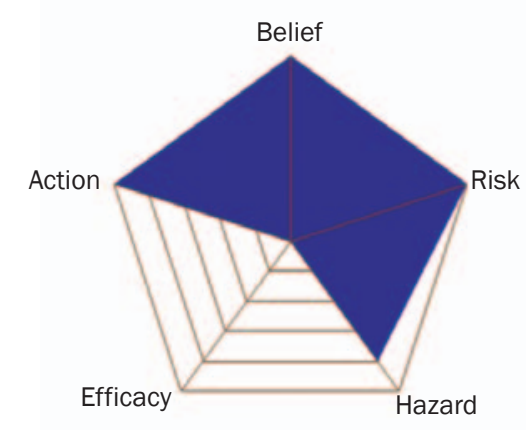

(c)

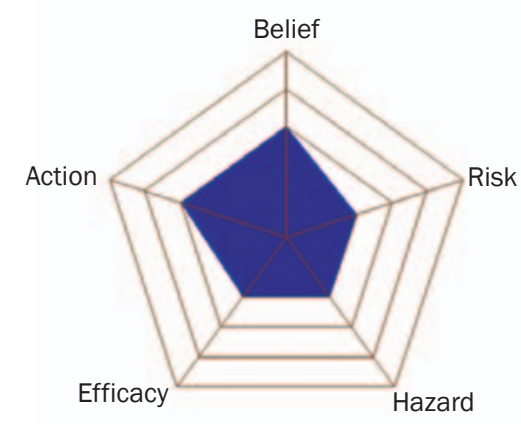

(e)

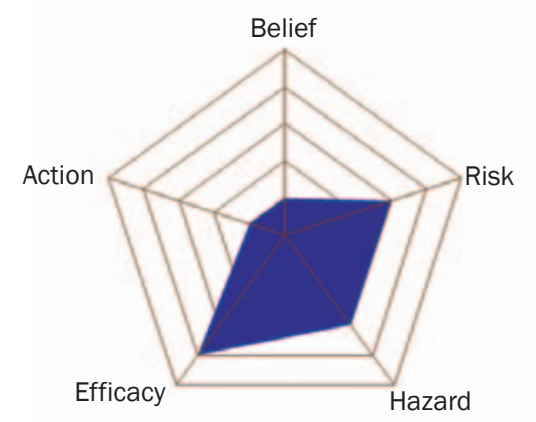

(b)

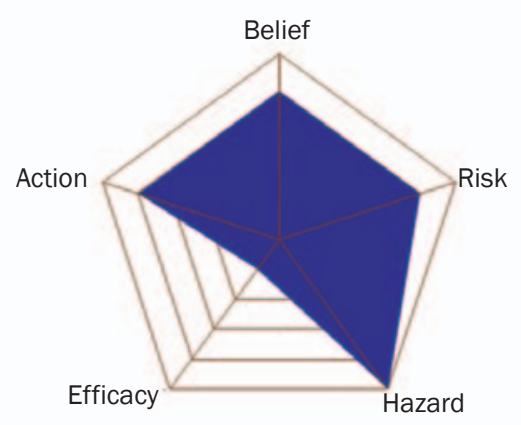

(d)

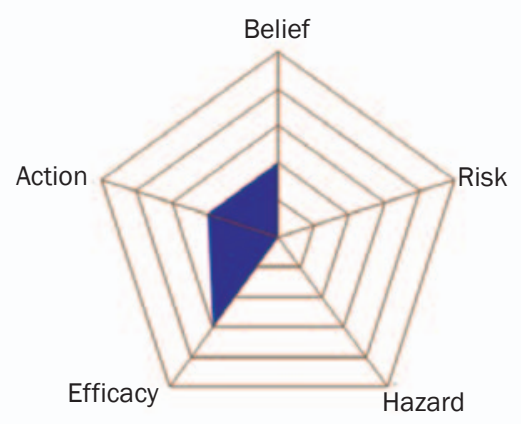

(f)

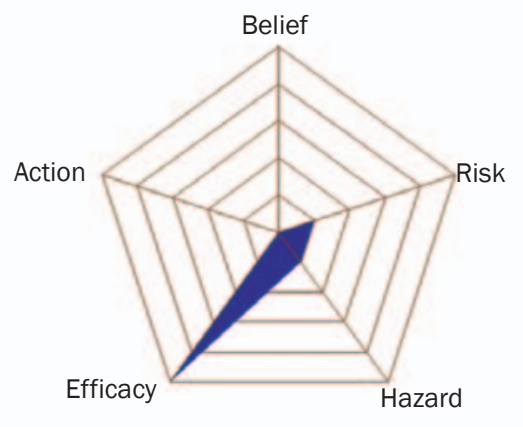

Figure 5 presents standardized means for each category of variable for the six classes. The spread between class scores is widest for the perceived risk category, followed by the belief and hazard categories. The mean scores cluster most closely for the efficacy category. In addition, with the exception of class 6 , the detached, the classes also cluster closely together on the adaptation and mitigation action items.

These findings have important implications for outreach programing. First, the closeness of scores on the efficacy measures indicates that farmers are most similar in their confidence that they will be able to use their knowledge, skills, and the tools available to them to adapt to future changes in climate. This finding supports Nowak's (2013) call to engage farmers as "active problem solvers" rather than passive clients, and suggests that such an approach could indeed be fruitful in extension efforts focused on adaptation.

Second, the finding that the support for action scores for classes 1 to 5 cluster together fairly closely points to other potential avenues for farmer engagement. Recall that 8 of the 10 action items focus on ways that farmers can deal with "increased weather variability" (table 1). As figure 3 shows, with the exception of class 6 (and to an extent, class 5), subgroups have similar scores on the eight items associated with adaptation to increases in weather variability (ACT1 to ACT6 and ACT9 and ACT10). In other words, these groups, which represent a great majority of the farmers in the sample, are relatively supportive of individual, private sector, and government action to support adaptation.

\section{Summary and Conclusions}

The effects of changing weather and climate present new challenges for agriculture. Though the risks and causes associated with changing climate conditions are widely debated, the impacts will need to be addressed in order for agriculture to continue to meet the world's growing needs for food, feed, fiber, and fuel (25 × '25 Alliance Adaptation Work Group 2013). The growing awareness that outreach with farmers and other natural resource user groups toward those ends must engage publics in dialogic, cooperative processes underscores the importance of in-depth understanding of target audiences (Groffman et al. 2010; Morton and Brown 2011). This analysis of Corn Belt farmer experiences with weather-related hazards, perceptions of risks associated with changing weather patterns, confidence in their capac- 


\section{Figure 5}

Comparison of standardized class means by question category. The means for the six classes are most similar for the efficacy and support for action categories of variables, pointing to potential common ground for engagement across classes.
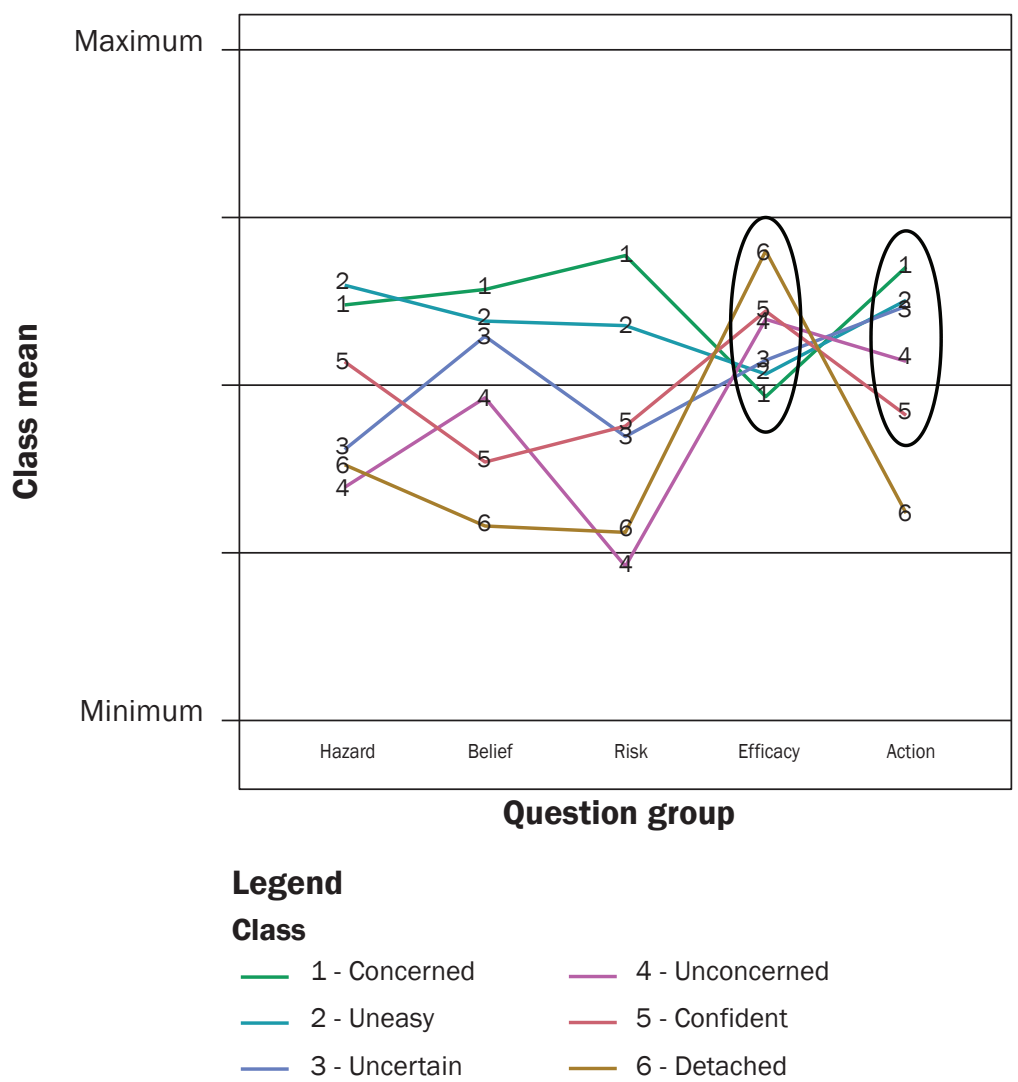

ities to address changing conditions, and willingness to support adaptation and mitigation reveals three key findings relevant to efforts to engage farmers in effective climate change-related outreach strategies.

A central finding is that farmers think about climate change and associated risks in different ways. The $39 \%$ of farmers that comprise classes 1 (the concerned) and 2 (the uneasy) are relatively engaged in thinking about climate change, worried about the potential impacts, and are supportive of public and private, individual, and collective action to address the risks and causes of climate change. Importantly, such farmers also tend to have experienced negative impacts of weather variability in recent years. Another $25 \%$ of farmers, the uncertain class (class 3 ), appear to be less concerned, but nonetheless tend to believe climate change is occurring, and are supportive of adaptation and mitigation at levels similar to those of classes 1 and 2 . Thus, while the $63 \%$ of farmers who were in classes 1 to 3 might vary in their responsive- ness to messages focused on climate change adaptation and mitigation, communication focused specifically on adaptive responses to climate change would likely resonate with most members of these classes.

On the other hand, the $37 \%$ of farmers who make up classes 4 to 6 tend not to believe that climate change is occurring, express much less concern about potential risks, are more confident in their capacity to adapt, and are not as apt to support action. Except for class 5 (the confident), these subpopulations report very little experience with adverse weather-related impacts on their farm operations over the previous five years. In contrast to classes 1 to 3 , outreach that is directly focused on responses to climate change would not likely resonate with farmers in these classes.

Thus, to a degree our findings are similar to those of the Six Americas studies, which have recommended that communications strategies take into account the substantial variation in public perspectives on climate change (Leiserowitz et al. 2013b; Maibach et al. 2011a). In agriculture, the $25 \times$ '25 Alliance Adaptation Communications and Engagement Work Group composed of leading agricultural and social scientists and communications experts emphasizes that a one-size-fits-all approach has limited effectiveness and recommends subdivision or segmentation of audiences into groups with similar beliefs, values, and interests, and designing public engagement efforts to speak to each group's unique situation $(25 \times$ '25 Alliance Adaptation Workgroup 2013). The results of this research support those recommendations.

A second major finding is the identification of potential areas of common ground that could serve as a foundation for the development of engagement approaches that resonate broadly with farmers. In practice, targeting segments or subgroups of populations can be difficult, so it is also important to develop outreach strategies that can engage farmers more broadly. The results showing similarities in farmer responses on the efficacy variables and the measures of support for adaptive management suggest that broad-based outreach strategies should focus on these areas rather than on areas such as beliefs about climate change on which results were more polarized.

Increasingly unpredictable and variable weather, disease and pest pressure, and other challenges will continue to create high levels of uncertainty and compel farmers to reevaluate past management decisions, seek new information and strategies, and take adaptive actions (Walthall et al. 2012). The results of this research indicate that many farmers feel confident that they can face these challenges, just as previous generations of farmers have adapted to challenges that they faced (OECD 2012). This suggests that engagement strategies that appeal to farmers' problem solving ability and feelings of efficacy could be an effective means of working with farmers toward more dialogic adaptive management processes.

Lastly, the language used to discuss climate science and adaptive management strategies likely will influence farmer willingness to learn more about and try more practices that can increase productivity and resilience and reduce environmental impacts. Farmers use narratives to interpret and give meaning to the tension between farming practices and the impacts of management decisions on the environment; listening to their word choices and the language of these narratives can provide guidance to gaining their attention 
and effective communication (Comito and Helmers 2011). In our models, the classes differed substantially on climate change beliefs (figure 3), and most farmers did not implicate human activity even if they indicated that climate change is occurring. Farmers such as those in the unconcerned, confident, and detached classes do not yet seem to have framed climate change as a problem. These findings support previous work that has suggested that engagement strategies targeting farmers more broadly should not focus overtly on the human role in climate change to avoid alienating the large swath of Corn Belt farmers who do not believe in anthropogenic climate change (Arbuckle et al. 2013b).

The similarities in mean class responses on items associated with adaptation to increased weather variability point to potential openings for engagement, however. Across the Corn Belt weather is becoming more variable and extreme events are becoming more common. Our results suggest that emphasizing terminology and narratives that focus on adaptation to weather variability rather than climate change may be better received and more effective when working with farmers.

This paper has several limitations. First, the sample is representative of larger-scale corn farmers in the Corn Belt region of the United States. Any generalization to smaller-scale farmers or farmers in other regions must be undertaken with caution.

Another limitation is related to the scope of the research presented. The analysis presented in this paper is exploratory, extending the general method of classification presented in Maibach et al. (2011a) to an important population of farmers. It does not, however, examine predictors of class membership (i.e., socioeconomic, farm structural, biophysical, and political economic variables), which could contribute substantially to our understanding of underlying causes of differences between classes and further enable effective climate change programming. Although such analyses were beyond the scope of this paper, future research will focus on analysis of the factors associated with variance in class membership with the goal of developing theory explaining the differences and similarities discovered in this paper.

The results of this research represent an advance in our understanding of perspectives on climate change among a population of farmers that farms nearly $80 \%$ of the land in the Corn Belt region and produces a sub- stantial proportion of the US and global corn crop. These findings can be used to inform both targeted outreach to subgroups of farmers in this population and more broad-based engagement strategies. Interface organizations such as university extension, farm organizations, and other groups whose mission includes use of science-based information to guide activities meant to maintain and improve the natural resource base on which agriculture depends (Osmond et al. 2010) can use the results of this research to help them work more effectively with farmers. Agriculture faces major challenges, and a concerted effort is needed to help farmers better understand the risks and adopt more effective strategies that can increase agroecosystem resilience and mitigate GHG emissions (Lal et al. 2011) To reach these goals, agricultural advisory groups must take both scientific knowledge and farmer perspectives into account Although some Corn Belt farmers will be receptive to explicit discussion of climate change and potential responses, terms such as weather variability and extreme weather will likely resonate with a greater proportion of farmers. As long as climate change remains a politically charged issue, this research suggests that engaging farmers in creative adaptation to their more immediate experiences (e.g., increased weather variability) rather than the causes (climate change) will be a more effective route to resilience.

\section{References}

$25 \times$ '25 Alliance Adaptation Work Group. 2013. Agriculture and Forestry in a Changing Climate: Adaptation Recommendations. Lutherville, MD: $25 \times$ '25 Alliance.

Akerlof, K., E.W. Maibach, D. Fitzgerald, A.Y. Cedeno, and A. Neuman. 2013. Do people "personally experience" global warming, and if so how, and does it matter? Global Environmental Change 23:81-91.

Ajzen, I. 2002. Perceived behavioral control, self-efficacy, locus of control, and the theory of planned behavior. Journal of Applied Social Psychology 32:665-683.

Anderegg,W.R.L., J.W. Prall, J. Harold, and S.H. Schneider. 2010 Expert credibility in climate change. Proceedings of the National Academy of Sciences 107(27):12107-12109.

Arbuckle, J.G. Jr., L.S. Prokopy, T. Haigh, J. Hobbs, T. Knoot, C. Knutson, A. Loy, A.S. Mase, J. McGuire, L.W. Morton, J. Tyndall, and M. Widhal. 2013a. Climate change beliefs, concerns, and attitudes toward adaptation and mitigation among farmers in the Midwestern United States. Climatic Change 117:943-950.

Arbuckle, J.G. Jr., L. Morton, and J. Hobbs. 2013b. Farmer beliefs and concerns about climate change and attitudes toward adaptation and mitigation: Evidence from Iowa. Climatic Change 118(3-4):551-563.

Bandura, A. 1991. Social cognitive theory of self-regulation. Organizational Behavior and Human Decision Processes 50:248-287

Berry, P.M., M.D.A. Rounsevell, P.A. Harrison, and E. Audsley. 2006. Assessing the vulnerability of agricultural land use and species to climate change and the role of policy in facilitating adaptation. Environmental Science \& Policy 9(2):189-204.

Brody, S.D., S. Zahran, A.Vedlitz, and H. Grover. 2008. Examining the relationship between physical vulnerability and public perceptions of global climate change in the United States. Environment and Behavior 40(1):72-95.

Brossard, D., and B.V. Lewenstein. 2010. A critical appraisal of models of public understanding of science. In Understanding and Communicating Science: New Agendas in Communication, eds. L. Kahlor and P. A. Stout, 11-39. New York, NY: Routledge.

Climate Change Position Statement Working Group. 2011. Position Statement on Climate Change. Madison, WI: Working Group Report, Agronomy Society of America, Crop Science Society of America, and Soil Science Society of America.

Comito, J., and M. Helmers. 2011. The language of conservation. In Pathways for Getting to Better Water Quality: The Citizen Effect, eds. L.W. Morton and S. Brown, 67-80. New York, NY: Springer.

Ding, D., E.W. Maibach, X. Zhao, C. Roser-Renouf, and A. Leiserowitz. 2011. Support for climate policy and societal action are linked to perceptions about scientific agreement. Nature Climate Change 1(9):462-466.

Doran, P.T., and M.K. Zimmerman. 2009. Examining the scientific consensus on climate change. Eos, Transactions American Geophysical Union 90(3):22-23.

Dunlap, R.E. 2013. Climate change skepticism and denial: An introduction. American Behavioral Scientist 57:691-698.

Gallup. 2012. U.S. Global Warming Views Steady Despite Warm Winter. Princeton, NJ: Gallup Inc.

Groffman, P.M., C. Stylinski, M.C. Nisbet, C.M. Duarte, R. Jordan, A. Burgin, and J. Coloso. 2010. Restarting the conversation: challenges at the interface between ecology and society. Frontiers in Ecology and the Environment 8(6):284-291.

Hatfield, J.L., D. Ort, A.M. Thomson, D. Wolfe, R.C. Izaurralde, K.J. Boote, B.A. Kimball, and L.H. Ziska. 2011. Climate impacts on agriculture: Implications for crop production. Agronomy Journal 103:351-370.

Howden, S.M., J.F. Soussana, F.N. Tubiello, N. Chhetri, M. Dunlop, and H. Meinke. 2007. Adapting agriculture to climate change. Proceedings of the National Academy of Sciences 104(50):19691-6.

Hulme, M. 2009. Why We Disagree about Climate Change. Cambridge: Cambridge University Press.

IFPRI (International Food Policy Research Institute). 2010. Food security, farming, and climate change: Scenarios, results, policy options. Washington, DC: International Food Policy Research Institute. 
IPCC (Intergovernmental Panel on Climate Change). 2007. Climate Change 2007: Synthesis Report, Summary for Policymakers. In Contribution of Working Groups I, II and III to the Fourth Assessment Report of the Intergovernmental Panel on Climate Change, eds. R.K. Pachauri and A. Reisinger. Geneva: Intergovernmental Panel on Climate Change.

Kahan D.M., H. Jenkins-Smith, and D. Braman. 2010. Cultural cognition of scientific consensus. Journal of Risk Research 14:147-174.

Kellstedt, P.M., A.Vedlitz, and S. Zahran. 2008. Personal efficacy, the information environment, and attitudes toward global warming and climate change in the United States. Risk analysis 28:113-126.

Lal, R., J.A. Delgado, P.M. Groffman, N. Millar, C. Dell, and A. Rotz. 2011. Management to mitigate and adapt to climate change. Journal of Soil and Water Conservation 66(4):27685, doi:10.2489/jswc.66.4.276

Leeuwis, C. 2004. Communication for Rural Innovation: Rethinking Agricultural Extension. Oxford: Blackwell Science.

Leiserowitz A., E. Maibach, C. Roser-Renouf, G. Feinberg, and P. Howe. 2013a. Extreme Weather and Climate Change in the American Mind: April 2013. New Haven, CT:Yale Project on Climate Change Communication.

Leiserowitz A., E. Maibach, C. Roser-Renouf, G. Feinberg, and P. Howe. 2013b. Global Warming's Six Americas, September 2012. New Haven, CT:Yale Project on Climate Change Communication.

Linzer, D.A., and J.B. Lewis. 2011. poLCA: An R package for polytomous variable latent class analysis. Journal of Statistical Software 42(10):1-29.

Loy, A., J. Hobbs J. Gordon Arbuckle Jr., L. Wright Morton, L.S. Prokopy, T. Haigh, T. Knoot, C. Knutson, A.S Mase, J. McGuire, J. Tyndall, and M. Widhalm. 2013. Farmer Perspectives on Agriculture and Weather Variability in the Corn Belt: A Statistical Atlas. Cropping Systems Coordinated Agricultural Project 0153-2013. Ames, IA Cropping Systems Coordinated Agricultural Project: Climate Change, Mitigation, and Adaptation in Cornbased Cropping Systems.

Magidson, J., and J. Vermunt. 2002. Latent class models for clustering: A comparison with K-means. Canadian Journal of Marketing Research 20(1):36-43.

Magidson, J., and J.Vermunt. 2004. Latent Class Models. In The Sage Handbook of Quantitative Methodology for the Social Sciences 175-198

Maibach, E.W., A. Leiserowitz, C. Roser-Renouf, and C.K Mertz. 2011a. Identifying like-minded audiences for global warming public engagement campaigns: An audience segmentation analysis and tool development. PLoS ONE 6(3):e17571, doi: 10.1371/journal.pone.0017571.

Maibach,E.W.,A. Leiserowitz, C. Roser-Renouf, C.K. Mertz, and K. Akerlof. 2011b. Global Warming's Six Americas screening tools: Survey instruments; instructions for coding and data treatment; and statistical program scripts. New Haven, CT: Yale University and George
Mason University. Yale Project on Climate Change Communication. http://climatechangecommunication. org/ SixAmericasManual.cfm.

McCarl, B.A. 2010. Analysis of climate change implications for agriculture and forestry: An interdisciplinary effort. Climatic Change 100(1):119-24.

McCright, A.M., and R.E. Dunlap. 2010. Anti-reflexivity: The American conservative movement's success in undermining climate science and policy. Theory, Culture \& Society 27(2):100-133.

Moser, S.C. 2010. Communicating climate change: History, challenges, process and future directions. Wiley Interdisciplinary Reviews: Climate Change 1:31-53.

Morton, L.W., and S. Brown. 2011. Pathways for Getting to Better Water Quality:The Citizen Effect. New York: Springer.

Myers, T.A., E.W. Maibach, C. Roser-Renouf, K. Akerlof, and A. Leiserowitz. 2013. The relationship between personal experience and belief in the reality of global warming. Nature Climate Change 3:343-347.

NRC (National Research Council). 2010. Adapting to the Impacts of Climate Change: America's Climate Choices. Washington, DC: National Academies Press.

Nigg, J.M., and D. Mileti. 2002. Natural Hazards and Disasters. In Handbook of Environmental Sociology, eds. R. E. Dunlap and W.Michelson, 272-294. Westport, CT: Greenwood Press.

Nisbet, M.C., and T. Myers. 2007. Twenty years of public opinion about global warming. Public Opinion Quarterly 71:444-470.

Nowak, P. 2013. Thinking about a future conservation agenda. Journal of Soil and Water Conservation 68(2):50A-52A, doi:10.2489/jswc.68.2.50A.

O'Connor,R.E.,R.J.Bord, and A. Fisher. 1999.Risk Perceptions, General Environmental Beliefs, and Willingness to Address Climate Change. Risk Analysis 19(3):461-471.

O'Connor, R.E., B.Yarnal, K. Dow, C.L.Jocoy, and G.J. Carbone. 2005. Feeling at Risk Matters: Water Managers and the Decision to Use Forecasts. Risk Analysis 25(5):1265-1275.

OECD (Organization for Economic Co-operation and Development). 2012. Farmer Behaviour, Agricultural Management and Climate Change: OECD Publishing.

Osmond, D.L., N.M. Nadkarni, C.T. Driscoll, E. Andrews, A.J. Gold, S.R. Broussard Allred, A.R. Berkowitz, M.W. Klemens, T.L. Loecke, M.A. McGarry, K. Schwarz, M.L. Washington, and P.M. Groffman. 2010. The role of interface organizations in science communication and understanding. Frontiers in Ecology and the Environment 8:306-313.

Pew Research Center. 2012. More Say There is Solid Evidence of Global Warming. Washington, DC: Pew Charitable Trusts.

R Core Team 2012. R: A language and environment for statistical computing. R Foundation for Statistical Computing,Vienna,Austria. ISBN 3-900051-07-0, http:// www.R-project.org/.

Rogers, E.M. 2003. Diffusion of Innovations (Fifth Edition) New York: Free Press.
Rogovska, N., and R.M. Cruse. 2011. Climate Change Consequences for Agriculture in Iowa. In Climate Change Impacts on Iowa 2010. Des Moines, IA: Office of Energy Independence.

Ruttan, V.W. 1996. What happened to technology adoptiondiffusion research? Sociologia Ruralis 36:51-73.

Spence, A., W. Poortinga, C. Butler, and N.F. Pidgeon. 2011. Perceptions of climate change and willingness to save energy related to flood experience. Nature Climate Change 1(1):46-49.

SWCS (Soil and Water Conservation Society). 2011. Position Statement on Climate Change and Soil and Water Conservation. Ankeny, IA: Soil and Water Conservation Society.

Theus, M. 2008. High-dimensional data visualization. In Handbook of Data Visualization, eds. C. Chen, W. K. Härdle, and A. Unwin, 151-178. Berlin: Springer.

USDA. 1994. Major World Crop Areas and Climatic Profiles, Agricultural Handbook No. 664. Washington, DC: World Agricultural Outlook Board, U.S. Department of Agriculture. http://www.usda.gov/oce/weather/pubs/ Other/MWCACP/.

USDA FAS (Foreign Agricultural Service). 2012. Production, Supply and Distribution Online Database. http://www.fas. usda.gov/psdonline/.

USDA NASS (National Agricultural Statistics Service). 2009. 2007 Census of Agriculture. Washington, DC: US Department of Agriculture National Agricultural Statistics Service.

USDA NASS. 2011. Crop Production 2010 Summary. http://usda.mannlib.cornell.edu/MannUsda/ viewDocumentInfo.do?documentID=1047.

Walthall, C.L., J. Hatfield, P. Backlund, L. Lengnick, E. Marshall, M.Walsh, S.Adkins, M.Aillery, E.A. Ainsworth, C.Ammann, C.J. Anderson, I. Bartomeus, L.H. Baumgard, F. Booker, B. Bradley, D.M. Blumenthal, J. Bunce, K. Burkey, S.M. Dabney, J.A. Delgado, J. Dukes, A. Funk, K. Garrett, M. Glenn, D.A. Grantz, D. Goodrich, S. Hu, R.C. Izaurralde, R.A.C. Jones, S-H. Kim, A.D.B. Leaky, K. Lewers, T.L. Mader,A. McClung, J. Morgan, D.J. Muth, M. Nearing, D.M. Oosterhuis, D. Ort, C. Parmesan, W.T. Pettigrew, W. Polley, R. Rader, C. Rice, M. Rivington, E. Rosskopf, W.A. Salas, L.E. Sollenberger, R. Srygley, C. Stockle, E.S. Takle, D. Timlin, J.W. White, R. Winfree, L. Wright Morton, and L.H. Ziska. 2012. Climate Change and Agriculture in the United States: Effects and Adaptation. Washington, DC: USDA

Weber, E.U. 2010. What shapes perceptions of climate change? Wiley Interdisciplinary Reviews: Climate Change 1(3):332-342.

Weber, E.U., and P.C. Stern. 2011. Public Understanding of Climate Change in the United States. American Psychologist 66:315-28.

Wegman, E.J. 1990. Hyperdimensional data analysis using parallel coordinates. Journal of the American Statistical Association 85(411):664-675. 